\title{
Research on the Status Quo and Countermeasures of Cross-Border E-Commerce Development in Arab Countries
}

\author{
Mohammed Abdo Ahmed Aqlan \\ College of Business Administration, SCUT, Guangzhou, China \\ Email: mdn84@ymail.com
}

How to cite this paper: Aqlan, M. A. A. (2020). Research on the Status Quo and Countermeasures of Cross-Border E-Commerce Development in Arab Countries. Open Journal of Business and Management, 8 , 1536-1542.

https://doi.org/10.4236/ojbm.2020.84097

Received: May 21, 2020

Accepted: July 10, 2020

Published: July 13, 2020

Copyright $\odot 2020$ by author(s) and Scientific Research Publishing Inc. This work is licensed under the Creative Commons Attribution International License (CC BY 4.0).

http://creativecommons.org/licenses/by/4.0/

\begin{abstract}
The development of modern information technology has subverted the previous trading methods. The rapid development of electronic information technology and logistics technology has laid a technical foundation for the development of cross-border e-commerce, and the huge market demand has accelerated the development of cross-border e-commerce. As a traditional energy supply region, Arab countries are also developing e-commerce. Although the current level of development of Arab countries in cross-border e-commerce cannot be compared with leading countries such as China and the United States, the consumption potential will be increased quickly based on the huge market demand of the Arab region, and it is recommended that Arab countries learn from China's successful experience, such as enriching various industrial structures, improving e-commerce laws and regulations, strengthening the construction of basic logistics facilities, and promoting the application of electronic payment scenarios and other countermeasures. This will greatly promote the development of cross-border e-commerce in the Arab region.
\end{abstract}

\section{Keywords}

Arab, E-Commerce, Development Status, Countermeasures

\section{Introduction}

People's demand for materials grows along with the development of economic level. The demand for materials in modern society not only requires rich varieties to be selected at will, reliable quality, but also the convenience of shopping. The development of Internet technology has brought people closer together. With the connection of the Internet, the whole world has formed a whole. 
People in the eastern hemisphere can communicate with people in the western hemisphere in real time. Intuitive understanding, and the development of e-commerce have provided convenience for people to buy goods across regions. Under the support of the rapid development of the Internet, a new business model-e-commerce came into being. Different from traditional trading methods, the biggest feature of the e-commerce model is its high efficiency and low cost, which saves a lot of intermediate expenses. Judging from the law of economic development, the development direction of transactions must be toward the lowest transaction cost. All sensible businessmen are profit-seeking, so the development of e-commerce has become a link that is highly valued by various economic powers. Japanese economic researcher (Takashima, 2013) believes that Internet-based electronic transactions will become the most mainstream transaction method in the near future. In China, where e-commerce is the fastest growing, almost everyone participates in online shopping. The participation of all people has greatly promoted the development of e-commerce in China. China has become the world's most advanced e-commerce technology and the country with the largest transaction volume.

In the Arab world, most countries lack the ability to produce and manufacture commonly used commodities, and people's demand for commodities is the same, so even if the development of e-commerce in Arab countries is not long, the speed is amazing in wealthy countries such as the UAE, Israel and Saudi Arabia. However, the Arab countries have insufficient experience in cross-border e-commerce and do not have a strong technical foundation to support them. However, China, as an Asian country, has achieved remarkable results in e-commerce. Arab countries can learn from China in e-commerce. The successful experience and corresponding countermeasures will help improve the e-commerce level of Arab countries.

\section{Theoretical Basis of E-Commerce}

The main types of e-commerce are $\mathrm{BTC}, \mathrm{BTB}, \mathrm{CTB}, \mathrm{OTO}, \mathrm{CTC}$, and other types such as BTM, MTC, BMC, S2C, BTE, ABC, PTP, etc. Regardless of the type of e-commerce, the essence of the process is the same. All use the Internet platform to establish a transaction system. Two or more parties to the transaction voluntarily conduct transactions on the system. This platform has been covered through years of development. It has all the basic elements required for trade: transaction partners, logistics trends, payment and transfer of funds, and real-time information transfer between each other, and has created a more efficient and convenient transaction mode than traditional trade.

The transaction object of e-commerce can be an organization or a person. The transaction can be formed between two parties or can be reached between multiple parties. This depends on the needs of the transaction and is mainly determined by the attributes of the transaction itself; e-commerce logistics, Capital flow and information flow form the basis of e-commerce trade, and it is also the 
main feature that distinguishes it from traditional trade. The first is the information flow. The information on the e-commerce business platform is open and easy to query. The large platform is very strict with the information review of merchants and users. This also guarantees the authenticity of the information on the platform and reduces people's search. The cost of information; and logistics is the decisive factor for the rapid development of e-commerce. Formally, because the modern logistics network is so developed, it has basically achieved the most efficient use and integration of transportation resources. While quickly meeting customer needs, e-commerce enterprises have been established. The logistics platform has improved technology and services from the entire logistics process of storage, transportation and delivery. The current e-commerce logistics system has become a multi-functional platform that can achieve a variety of services; while fund payment and professional security and efficiency are the basic condition for people to choose an e-commerce platform. Only when they can ensure that their interests are not damaged, people will choose to continue trading on this platform. The role of the e-commerce platform is to play a role in supervision and regulation. Formulate specifications to ensure that transactions are legal, reasonable, and fair.

\section{Status of Cross-Border E-Commerce in Arab Countries}

According to statistics from the relevant data, the size of the e-commerce market in Arab countries increased from US $\$ 91.6$ billion in 2013 to US $\$ 174$ billion in 2019. The specific growth trend is shown in Figure 1. There are three types of B2C, B2B, and G2B/C (government to companies and individuals) that account for the main share of e-commerce business in Arab countries, totaling more than $75 \%$. In the information collected by China's e-commerce research center in 2019, it can be found that the e-commerce market in the Arab countries has a large scale. Preliminary estimates indicate that the annual e-commerce business volume of the Arab countries has approached $\$ 200$ billion. The mark, more than 200 billion US dollars is likely to be in 2020 .

Among the many Arab countries, the e-commerce development level of each country is also quite different. Statistics from a management consulting firm (Kearney, 2018), show the current share of the Arab country's e-commerce market, the UAE has a 53\% market share, Saudi Arabia has 14\%, and Oman $12 \%$, Qatar $10 \%$. The UAE's high market share is mainly due to its relatively rich domestic market, high national network coverage, convenient access for residents, and high per capita consumption levels. The transaction volume of the e-commerce market in several major countries in the Arab world in 2019 is shown in Figure 2. As can be seen from Figure 2, the UAE is the country with the largest e-commerce market in the Arab region. In a Japanese article, Research on the Arab Electronic Commerce Market (Yuji, 2013), authoritative industry analysts predicted that the UAE's e-commerce industry will grow by more than $5 \%$ in 2020 , and hopefully exceed US $\$ 50$ billion. 


\section{3-2019 Arab countries e-commerce market size}

\section{(100 million US dollars)}

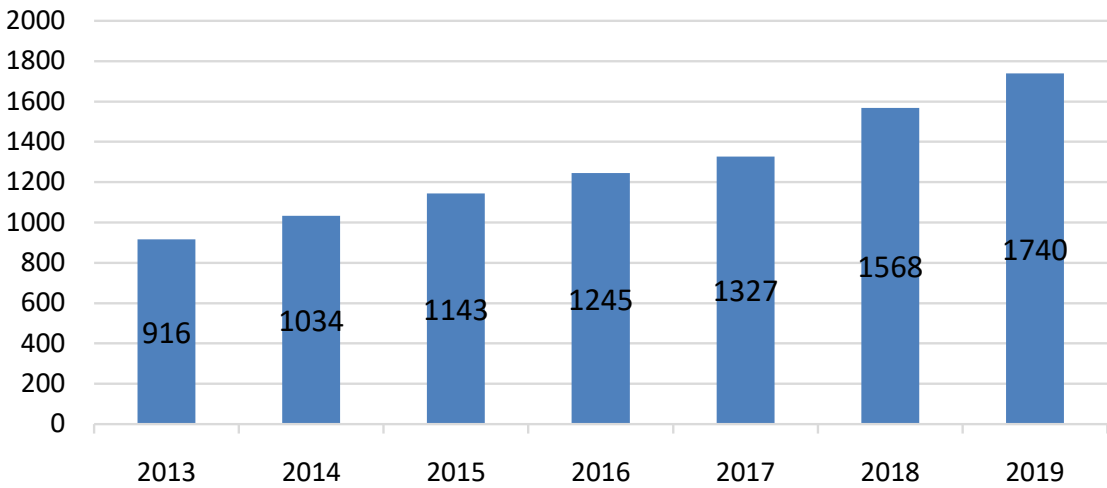

Figure 1. 2013-2019 Arab region e-commerce market size.

\section{E-commerce transactions in Arab countries in 2019 (100 million USD)}

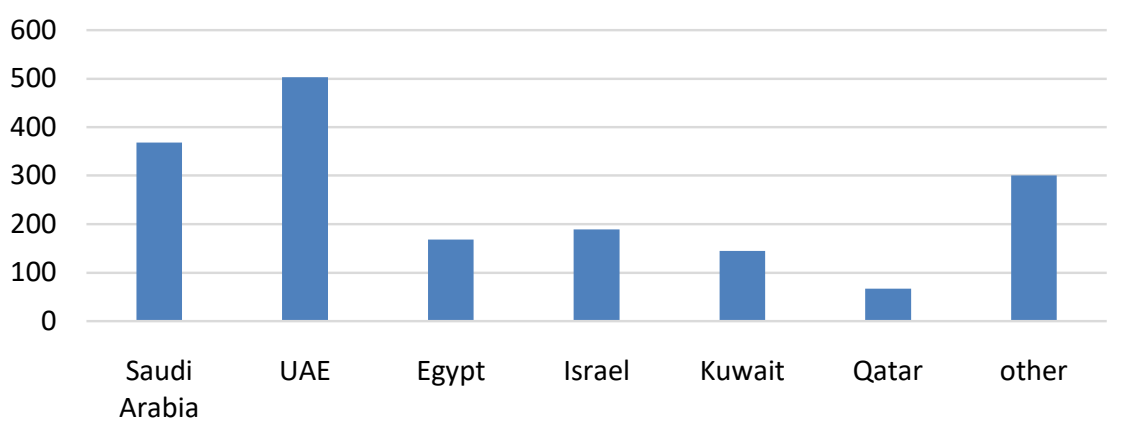

Figure 2. E-commerce transactions in Arab countries in 2019/USD 100 million.

According to head of the consulting agency Frost \& Sullivan of the Gulf Arab States Federation (Singh, 2019), cross-border e-commerce sales in Arab countries will increase by $40 \%$ to USD 41.5 billion in 2020. Judging from the basic network facilities in Arab countries, most Arab countries currently have network coverage of over $80 \%$. It is very convenient and fast for residents to use mobile phones to access the Internet. In rich countries like the UAE and Saudi Arabia, there are already $60 \%$ - 70\% People use mobile phones to surf the Internet, and the per capita consumption in these two countries exceeded the level of US $\$ 10,000$ and US\$20,000 respectively in 2019.

Although the Arab cross-border e-commerce market developed late, its cross-border e-commerce development is still in the initial development stage of small scale and low penetration, but it is at a stage of high growth. In 2018, the major economically developed countries in the Arab region, such as Saudi Israel, had cross-border e-commerce turnovers of US $\$ 1.387$ billion, US $\$ 1.211$ billion, US $\$ 429$ million, and US $\$ 2.626$ billion. See Figure 3. Cross-border e-commerce penetration rates were $25 \%, 46 \%, 8 \%$, and $9 \%$, respectively. Although this data 


\section{Distribution of cross-border e-commerce of Arab region in 2018}

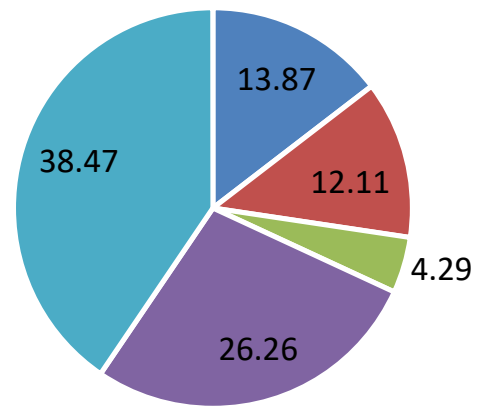

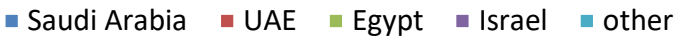

Figure 3. Distribution of online retail sales in the Arab region in 2018.

cannot be considered high, the growth rate is indeed gratifying. The average growth rate in the past three years has exceeded $30 \%$.

Considering that the Arab region has a population of more than 300 million, a common religious and cultural foundation, and no communication barriers in language, cross-border e-commerce in the Arab world has a broad space for development, and the wealth of the Arab region is unmatched by other regions Yes, this huge market will surely attract the participation of e-commerce giants from all over the world. The Arab countries in the future will definitely play a pivotal role in the cross-border e-commerce market worldwide.

\section{Countermeasure Research on Arab Cross-Border E-Commerce}

Arab countries such as Saudi Arabia and the UAE are located in the same Asian region as China, and have the inherent geographical advantage of cross-border electronic transactions. Relying on its strong manufacturing capabilities, China is constantly exporting its own commodities, which has also laid the foundation for the development of trade between Arab countries and China. In this international context, China's e-commerce trade development model is more meaningful for Arab countries. Learning from China's successful experience will help promote the development of Arab countries' cross-border e-commerce. Through research on China's current cross-border e-commerce model and comparative analysis with the current situation of cross-border e-commerce in Arab countries, it is recommended that Arab countries take the following countermeasures to strengthen the development of cross-border e-commerce.

1) Establish the Arab country's own commodity manufacturing system, get rid of the single economic structure model, and gradually improve the Arab country's own commodity market. At present, the manufacturing industry in Arab countries is basically built on the petrochemical or mineral smelting industry, 
and there is no manufacturing capacity for light industrial consumer products, and this is precisely what is necessary for people's lives. Without the ability to manufacture commodities, they cannot naturally provide rich if you can choose consumer products online, people in the Arab world will naturally cultivate the habit of online consumption.

2) Establish basic laws suitable for the development of e-commerce, formulate special regulations for cross-border e-commerce, and provide legal foundation support for the development of cross-border e-commerce. The reason why China's e-commerce can flourish is inseparable from the strong support of the Chinese government. China's government departments have made every effort to establish specifically applicable laws for e-commerce-related financial management and capital protection, ensuring the e-commerce industry. In the course of development, there are very few situations that contradict current laws. The Arab countries have almost no experience in this area. Learning these mature laws and regulations has a strong reference significance for Arab countries.

3) Improve the construction of e-commerce supporting logistics. The level of logistics services is also an important basis for judging e-commerce services. The construction of logistics infrastructure requires government support and a large amount of capital investment. The governments of Arab countries can combine logistics infrastructure construction with urban transportation construction to attract foreign Capital enters and at the same time builds its own system with the help of foreign technology.

4) Establish an independent payment system for e-commerce transactions in the Arab world. Convenient third-party payment is also the basic element of the rapid development of China's e-commerce. China's Alipay and WeChat have almost covered most of the Asian countries and some developed countries. The Arab countries currently do not have their own third-party payment tools. Inventing a convenient payment method that can be used universally in the Arab region will break through the cross-border e-commerce barriers between Arab countries and help promote the payment or consumption habits with Arab characteristics to the world.

\section{Conclusion}

In general, the Arab market has huge room for e-commerce development. Its strong economic and Internet foundation and fast-growing online sales have provided strong support for the development of cross-border e-commerce. If the Arab countries can establish the infrastructure and market rules for e-commerce development with the help of foreign technology and capital, the e-commerce market in the Arab countries will explode.

\section{Conflicts of Interest}

The authors declare no conflicts of interest regarding the publication of this paper. 


\section{References}

Kearney, A. T. (2018). A Comparative Study of e-Commerce between China and West Asian Countries. SME Management and Technology, No. 32, 49-50.

Singh (2019). China to Arab Cross-Border e-Commerce Cooperation Research. Fujian Quality Management, No. 10, 20.

Takashima (2013). Analysis of Elements and Influencing Factors of e-Commerce Model. Economist, No. 2, 31-34.

Yuji, T. (2013). Research on the Arab Electronic Commerce Market. Modern Japanese Economy, No. 3, 68-79. 